\title{
H 387 A, HÍBRIDO TRILINEAL DE MAÍZ DE GRANO AMARILLO ADAPTADO A REGIONES SUBTROPICALES DE MÉXICO
}

\section{H 387 A, THREE-WAY YELLOW KERNEL MAIZE HYBRID ADAPTED TO SUBTROPICAL REGIONS OF MEXICO}

\author{
Ricardo E. Preciado-Ortiz*, Arturo D. Terrón-Ibarra', Ma. Gricelda \\ Vázquez-Carrillo² y Noel 0. Gómez-Montiel ${ }^{3}$
}

${ }^{1}$ Instituto Nacional de Investigaciones Forestales, Agrícolas y Pecuarias (INIFAP), Campo Experimental Bajío, Celaya, Guanajuato, México. ${ }^{2}$ INIFAP, Campo Experimental Valle de México, Texcoco, Estado de México. ${ }^{3}$ INIFAP, Campo Experimental Iguala, Iguala, Guerrero, México.

*Autor para correspondencia (preciado.ernesto@inifap.gob.mx; repreciado@yahoo.com)

En México existe una creciente demanda de maíz (Zea mays L.) de grano amarillo que se emplea como materia prima del sector agropecuario e industrial; su consumo ascendió a 15.3 millones de toneladas en el año 2016 (FIRA, 2016). Gran parte de esta demanda se concentra en las regiones del centro y occidente del país, donde existen importantes cuencas lecheras y numerosas granjas porcícolas y avícolas. En esas regiones, el maíz de grano amarillo, que se utiliza en la elaboración de alimentos balanceados, suma el 76 \% de la demanda y el resto se emplea en procesos industriales (FIRA, 2016). Debido a lo anterior, las áreas subtropicales productoras de maíz desempeñan un papel estratégico para abastecer a las regiones de mayor demanda. En los últimos años México importó el 80 \% de la demanda total de maíz de grano amarillo, que en 2016 fue de 12.2 millones de toneladas (FIRA, 2016); esto repercute en la balanza comercial y compromete la seguridad alimentaria del país.

Para revertir el déficit de producción de maíz amarillo es necesario que los actores involucrados en la cadena agroalimentaria del maíz implementen estrategias que incidan en la producción, comercialización y distribución de este grano. Al respecto, el Programa de Mejoramiento Genético de Maíz del Instituto Nacional de Investigaciones Forestales, Agrícolas y Pecuarias (INIFAP), con sede en el Campo Experimental Bajío (CEBAJ), pone a disposición de los productores de las regiones subtropicales el híbrido $\mathrm{H}$ 387 A, como una alternativa para incrementar la producción de maíz amarillo y contribuir a satisfacer la demanda de este grano en tales regiones.

El H 387 A es un híbrido trilineal formado por el progenitor femenino (CML $451 \times C M L 481)$ y LAB 1, como progenitor masculino. La denominación, genealogía e institución obtentora de los progenitores se describen en el Cuadro 1. La línea CML 451 es de 12 autofecundaciones; combina germoplasma cristalino proveniente de México, Colombia, el Caribe, Ecuador, Argentina y Centroamérica. En su obtención se enfatizó la selección para rendimiento, resistencia a pudrición de mazorca y acame de tallo y de raíz; se derivó del Pool 25 del CIMMYT, denominado Amarillo Cristalino Tardío Tropical (TLYF, por sus siglas en inglés); se desarrolló a través de selección por el método genealógico y cruzas de prueba.

Por su parte, la línea CML 481 tiene ocho autofecundaciones, se formó a través del avance y selección per se y con probadores en diversos ambientes, es de grano amarillo cristalino, ciclo tardío, resistente a mildiú velloso y a virus del rayado fino. Esta línea se derivó del Ciclo 11 de selección recurrente de líneas $S_{1}$ de la población Suwan-1, originaria de Tailandia. Esta población presenta buena heterosis con Tuxpeño y se seleccionó a

Cuadro 1. Denominación, genealogía e institución obtentora de los progenitores del híbrido trilineal H 387 A.

\begin{tabular}{|c|c|c|c|}
\hline & Parental A & Parental B & Parental C \\
\hline Denominación & CML 451 & CML 481 & LAB 1 \\
\hline Genealogía & $\begin{array}{l}[\mathrm{NPH} 28-1 * \mathrm{G} 25) \star \mathrm{NPH} 28]-1-2-1- \\
1-3-1-\mathrm{B} * 6\end{array}$ & SW1(S)C11-14-1-3-3-B*4 & 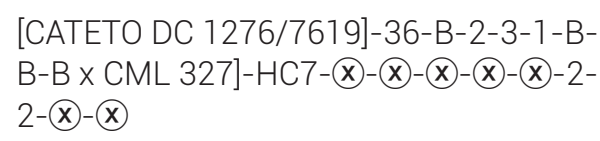 \\
\hline Obtentor & CIMMYT & CIMMYT & INIFAP \\
\hline
\end{tabular}


partir del Compuesto Thai \#1 formado a través de cinco ciclos de selección y retrocruzamiento con materiales resistentes a mildiú velloso. Thai \#1 involucra 36 fuentes de germoplasma: 16 de las islas del Caribe, seis de México y Centroamérica, cinco de Sudamérica, cinco de la India y cinco integradas por combinaciones de materiales de clima templado con Tuxpeños y del Caribe (Sriwatanapongse et al., 1993).

El progenitor masculino LAB 1 es una línea de nueve autofecundaciones, obtenida a través del método genealógico por el Programa de Maíz del INIFAP en el CEBAJ. El proceso de selección y avance endogámico, así como cruzamientos con probadores para identificar su respuesta heterótica inició en 2004. Su origen proviene de una generación avanzada de la cruza entre una línea experimental de nueve autofecundaciones derivada de Cateto (complejo de maíces cristalinos de Sudamérica) por CML 327, que es una línea de ocho autofecundaciones derivada de la Población 45, denominada Amarillo Bajío. La Población 45 es de amplia base genética, madurez intermedia y grano amarillo dentado, formada con germoplasma subtropical y templado de México, el Caribe y de la Faja Maicera de Estados Unidos. En su integración se enfatizó la selección para rendimiento, cobertura de mazorca, resistencia a pudrición de mazorca, tizón foliar (Exserohilum turcicum) y acame de tallo y de raíz (CIMMYT, 1998).

El híbrido H 387 A se registró en el año 2018 en el Catálogo Nacional de Variedades Vegetales del Servicio Nacional de Inspección y Certificación de Semillas, correspondiéndole la clave MAZ-1853-090318 (SNICS, 2018). Este híbrido se caracteriza por su alto potencial de rendimiento, ciclo de madurez intermedio-tardío, porte alto, tolerancia al acame, buena cobertura, estigmas con antocianinas de intensidad intermedia, espiga muy larga, ramas laterales primarias abundantes y presencia ocasional de ramas laterales secundarias. Presenta mazorca sana de tamaño grande, con 14 a 16 hileras, color de grano amarillonaranja y la forma de la corona es hendida (Figura 1). El progenitor femenino (la cruza simple) es de alto potencial de rendimiento, ciclo intermedio-tardío, grano amarillo semicristalino, porte alto, mazorcas largas, delgadas, hileras rectas, espiga muy larga, abierta, abundantes ramas laterales primarias. El progenitor masculino es de ciclo intermedio-tardío, porte de planta intermedio, hileras en espiral, estigmas de color rojo, grano semicristalino, amarillo-naranja y espiga mediana compacta.

En evaluaciones de campo efectuadas en los años 2014 2015 y 2016 en 13 ambientes del subtrópico, el H 387 A presentó un rendimiento de grano promedio de $11.9 \mathrm{t} \mathrm{ha}^{-1}$ y un intervalo de 7.4 a $15.7 \mathrm{t} \mathrm{ha}^{-1}$, así como intervalos de floración masculina entre 69 y 80, y femenina entre 70 y 81 días, altura de planta de 160 a $345 \mathrm{~cm}$ y de mazorca de 83 a $195 \mathrm{~cm}$; así mismo, como parte del ensayo uniforme de híbridos de grano amarillo de la red de evaluación de MasAgro, durante el ciclo PV 2016, el H 387 A quedó en tercer lugar en rendimiento, con $8.47 \mathrm{t} \mathrm{ha}^{-1}$ en promedio de 51 ambientes en diversos estados del país.

En el Cuadro 2 se muestra el rendimiento de grano y de algunas características físico-químicas del H 387 A

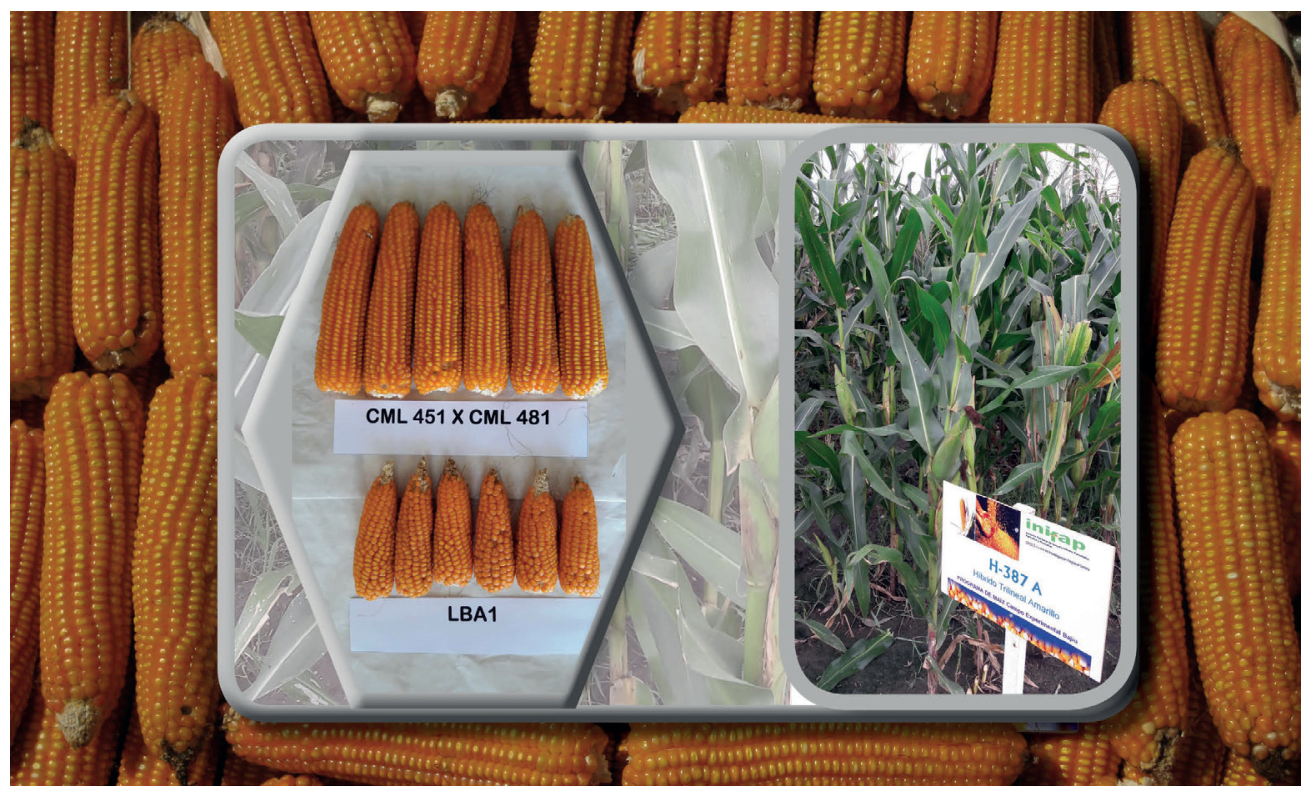

Figura 1. Mazorcas del maíz híbrido H 387 A y de sus progenitores. 
Cuadro 2. Rendimiento y características de calidad de grano del H 387 A, promedio de ocho ambientes subtropicales en los ciclos P-V 2015 y 2016.

\begin{tabular}{|c|c|c|c|c|c|c|c|c|}
\hline \multirow[t]{2}{*}{ Genotipo } & $\begin{array}{l}\text { Rendimiento } \\
\text { de grano }\end{array}$ & $\begin{array}{l}\text { Índice de } \\
\text { flotación }\end{array}$ & $\begin{array}{c}\text { Peso de } \\
\text { cien granos }\end{array}$ & $\begin{array}{c}\text { Peso } \\
\text { hectolítrico }\end{array}$ & $\begin{array}{c}\text { Contenido } \\
\text { de aceite }\end{array}$ & $\begin{array}{l}\text { Contenido } \\
\text { de almidón }\end{array}$ & $\begin{array}{c}\text { Contenido } \\
\text { de proteínas }\end{array}$ & \multirow{2}{*}{$\begin{array}{c}\text { Contenido de } \\
\text { carotenos } \\
\left(\mu \mathrm{g} \mathrm{g}^{-1}\right)\end{array}$} \\
\hline & $\left(\mathrm{t} \mathrm{ha}^{-1}\right)$ & $(\%)$ & (g) & $\left(\mathrm{kg} \mathrm{hL}^{-1}\right)$ & \multicolumn{3}{|c|}{ (\%) } & \\
\hline H 387 A & $12.17 \mathrm{a}$ & $5.09 \mathrm{c}$ & $34.49 \mathrm{c}$ & 82.68 a & $4.34 \mathrm{~b}$ & 70.24 a & $9.06 \mathrm{~b}$ & 12.2 a \\
\hline DK 2027 Y & 12.80 a & 20.78 a & 38.68 a & 78.62 b & $5.13 \mathrm{a}$ & 69.03 b & $9.15 \mathrm{~b}$ & $2.52 \mathrm{~b}$ \\
\hline $\mathrm{H}-377$ & $10.05 \mathrm{~b}$ & $15.63 \mathrm{~b}$ & $35.23 b$ & $78.51 \mathrm{~b}$ & $5.07 \mathrm{a}$ & $69.10 \mathrm{~b}$ & 9.49 a & \\
\hline DMS (0.05) & 1.87 & 2.17 & 0.62 & 0.72 & 0.23 & 0.65 & 0.32 & 2.30 \\
\hline
\end{tabular}

Medias con letras iguales en cada característica no son estadísticamente diferentes $(P \leq 0.05)$.

en comparación con los testigos comerciales DK 2027 Y de grano amarillo y H 377 de grano blanco, promedio de ocho ambientes establecidos durante primavera-verano (P-V) 2015 y 2016. Se observa que H 387 A presentó un rendimiento estadísticamente similar al testigo de grano amarillo y superior al testigo de grano blanco; así mismo, $\mathrm{H}$ 387 A mostró un índice de flotación muy bajo, indicativo de un grano muy duro, altos valores de peso hectolítrico, alto contenido de almidón y de carotenos, granos de tamaño mediano, con menor contenido de aceite y proteína que los testigos.

El H 387 A representa una alternativa para incrementar la producción de maíz de grano amarillo en las regiones subtropicales de México. La semilla básica del progenitor masculino (LAB 1) y la semilla de categoría registrada del progenitor femenino (CML $451 \times C M L$ 481) están disponibles, previa solicitud al INIFAP, para los interesados en la producción de semilla certificada del híbrido.

\section{BIBLIOGRAFÍA}

CIMMYT, Centro Internacional de Mejoramiento de Maíz y Trigo (1998) A Complete Listing of Improved Maize Germplasm From CIMMYT. Maize Program Special Report. CIMMYT. Mexico, D. F. 94 p.

FIRA, Fideicomisos Instituidos en Relación con la Agricultura FIRA (2016) Panorama Agroalimentario. Maíz 2016. Dirección de Investigación y Evaluación Económica y Sectorial. FIRA, Banco de México. México, D. F. 40 p.

SNICS, Servicio Nacional de Inspección y Certificación de Semillas (2018) Catálogo Nacional de Variedades Vegetales. 1er Trimestre 2018. Servicio Nacional de Inspección y Certificación de Semillas, SAGARPA. Ciudad de México. https://www.gob.mx/cms/ uploads/attachment/file/321761/CNVV1erTrimestre2018.pdf (Diciembre, 2018)

Sriwatanapongse S., S. Jinahyon and S. K. Vasal (1993) Suwan-I. Maize from Thailand to the World. CIMMYT. Mexico, D. F. 16 p. 
